STUDIA UBB PSYCHOL.-PAED., LXVI, 2, 2021, p. 39 - 57

(Recommended Citation)

DOI:10.24193/subbpsyped.2021.2.02

\title{
FOSTERING SCHOOL ENGAGEMENT IN CHILDREN FROM DISADVANTAGED COMMUNITIES
}

\section{ADRIAN OPRE ${ }^{1}$, RAMONA BUZGAR ${ }^{2 *}$, SEBASTIAN PINTEA1, DANA OPRE1', EUGEN SECARĂ ${ }^{1}$}

\begin{abstract}
In the last two decades, most of the Romanian mitigate programs aimed at reducing school dropout, have often focused only on remedial activities. However, keeping students in school for as long as possible involves increasing their school engagement, and therefore developing dimensions that target social and emotional skills is strongly recommended. In the present study, 130 primary and secondary school students from disadvantaged backgrounds, participated for 8 months in remedial and personal development activities, whose medium-term goal is to reduce school dropout. Using scales from the BASC ${ }^{3}$ and ASEBA ${ }^{4}$ psychological test batteries, we were able to capture significant effects of the intervention in reducing emotional problems and increasing students' adaptability to school-specific tasks, even though the pandemic imposed several restrictions on activities. The collected data revealed two important outcomes. First, they confirmed the effectiveness of a complex, multilevel program, which can develop the socio-emotional abilities of children at risk of dropping out of school. Second, they help us to highlight several factors that can predict its effectiveness. We consider that these empirical data constitute a solid foundation based on which similar future programs can be designed and implemented.
\end{abstract}

Keywords: school dropout, school engagement, social and emotional competencies, disadvantaged communities

${ }^{1}$ Babes-Bolyai University, Department of Psychology, adrianopre@psychology.ro

2 University of Agricultural Sciences and Veterinary Medicine Cluj-Napoca, Teacher Training Department

* Corresponding author: ramona.buzgar@usamvcluj.ro

${ }^{3}$ BASC - Behavior Assessment System for Children-2

${ }^{4}$ ASEBA - Achenbach System of Empirically Based Assessment 
ADRIAN OPRE, RAMONA BUZGAR, SEBASTIAN PINTEA, DANA OPRE, EUGEN SECARĂ

\section{Introduction}

At the beginning of 21st century, one of the biggest problems faced by many educational systems is students' disengagement from school. In 2016, OECD (Organization for Economic Cooperation and Development) reported that more than $27 \%$ of the adolescents evaluated from 72 countries felt disaffected from school. Twenty-six percent of the pupils said they skipped at least one class in the last two weeks before the evaluation, and $20 \%$ reported missing the entire school day at least once. In Romania, $87.8 \%$ of the evaluated adolescents reported they feel like an outsider (or left out of things) at school, and $15.6 \%$ said they feel awkward and out of place in their school (OECD 2017). We also know that in our country, school dropout has a high rate $(15.8 \%$, according to Eurostat in 2020) and almost 50\% of the students older than 15 years old have paid jobs, before or after school (OECD, 2017). These data can support the need for schools, government, NGOs and educational stakeholders to get involved in an active process to reduce school dropout. Given the fact that student disengagement seems to grow as students advance in the school system (Lam et al., 2015) and can be more severe for males, minority, and low-income students (Martin, Way, Bobis, \& Anderson, 2014), we believe that prevention might be an important key in this matter. Prevention is the process through which students can be equipped with abilities/skills that can function as protective factors in the future, and this is an important aspect that should be acknowledged by teachers, school counselors, school leaders, etc. Taking into account all these aspects, regarding school drop-out, it becomes essential to find solutions that will help keep students in school for as long as possible. There are, of course, several reasons: a. Empirical studies have repeatedly shown that engagement in academic activities is a prerequisite for learning and information retention (Shernoff, Ruzek and Sinha, 2016); b. student involvement is one of the robust predictors of academic achievement (Green et al., 2012). c. if we can increase student engagement, this might be the key to preventing early school leaving (Archambault, Janosz, Fallu, \& Pagani, 2009). And as we know, young people who drop out of school are more likely to be unemployed, earn low wages, face poverty and social exclusion, and rely heavily on public services (Rumberger, 2011). 
School engagement refers to a multifaceted concept with interrelated and mutually supportive dimensions as behavioral, emotional, and cognitive engagement (Fredericks, Blumenfeld, \& Paris, 2004; Pino-James et al., 2019). The first dimension refers to the degree to which students get involved in-class activities (e.g. following the rules), the second one refers to the positive and negative emotions derived from classwork, and cognitive engagement is related to the effort to complete classroom tasks, to process information. Although studies in this field are not always consonant with the definition of the concept of school engagement, in recent years a special emphasis has been placed on identifying the factors that could support it. Thus, the climate in which the classes take place, the trusting relationship that the teacher has with the student, the emotional and cognitive support, the good relations with classmates, fostering competence and autonomy, the support from the family and the school, all these are indicators that can support the student's commitment in the educational process (e.g. Furrer and Skinner, 2003; Brown, 2004; Skinner \& Pitzer, 2012; Patall et al., 2017).

Based on these records, we considered it appropriate to develop school engagement in the case of children at risk of high school dropout. Based on the long collaboration between the Romanian Patriarchate, the World Vision Romania Foundation, Babes-Bolyai University, and the Consult Plus company, in 2019 the foundations of a new project were laid. It aimed to reduce school dropout through an intervention program that integrated two types of activities: a. Remedial activities - aimed at recovering academic deficits; b. group or individual counseling activities - which aimed at developing social and emotional skills designed to support the child in the effort to meet school challenges. The intervention proposed in the project was a wide one and brought together several ways of intervention: 1 . a training program for teachers and school counselors who took on the counseling of children to develop their socio-emotional skills; 2. counseling activities addressed to parents of preschool children; 3. remedial and psycho-educational activities addressed to preschoolers, primary and secondary school students. Because most of the studies mentioned in the introductory section had students as a target group, for this paper we have extracted and will present only the results of the intervention designed for primary and secondary school students. 


\section{Aims of the study}

The purpose of this research was to evaluate the impact that the School for all - access to quality education for preschoolers, schoolchildren, and teachers project, carried out in several rural communities from Cluj County had on the social and emotional development of students from the target group. The project was accomplished within the project POCU / 74/6/18/104571 School for all - access to quality education for preschoolers, schoolchildren and teachers from the Nord-West Region" with the core purpose to prevent school dropout. Also, we aimed at exploring several social and demographic correlates of school engagement, to check the effectiveness of the program.

Because in this research project, the group of participants was selected based on certain specific criteria, all objectives were strictly related to the intervention group. Specifically, we aimed to prove that at the end of the program students who have benefited from the activities included will record improvements in adaptability, social skills, learning abilities, affective problems, anxiety problems, and ADHD problems.

\section{Measurements}

The battery of psycho-pedagogical tests used in our investigative approach consisted of several scales that evaluated the 5 categories of "academic activators" according to DiPerna, Volpe, and Elliot (2002). Due to the restrictions generated by the COVID 19 crisis, in both evaluation moments, these instruments were completed online. These constrains have forced us to choose only those tests that had a teacher report form. Moreover, this criterion was also important because the participants selected to participate in the intervention come from disadvantaged backgrounds, with very low access to technology (PC, laptop, iPad), but also with low digital skills (difficulties in filling in google forms documents). Thus, we chose the BASC-2-TRS test batteries (Behavior Assessment System for Children-2- Teacher Rating Scale, Reynolds \& Kamphaus, 2004, translated and adapted by Mitrofan N, Ion A. \& Iliescu D. in 2011) and ASEBA -TRF (Achenbach System of Empirically Based Assessment- Teacher Report Form, Achenbach \& Rescola, 1991, translated and adapted by Dobrean et al. in 2007). This complex psychological battery is validated in the Romanian population. 
From the BASC assessment system, we used the scales of adaptability, social skills, and learning skills, and from ASEBA, the scale of emotional problems, anxiety problems, and ADHD problems scale.

The questionnaires include items evaluated on a 3 or 4 points Likert scale, with which allowed their transposition in the google forms application to be completed online.

\section{Participants}

The participants in this research project were selected based on the POCU project requirements. Namely, we have included children from disadvantaged backgrounds, from families with low socioeconomic status, with parents working abroad and living in rural areas from Cluj County. Although at the beginning of the program (pre-intervention stage), teachers filled in evaluation forms for 117 primary school students and 132 secondary school students, at the end of the intervention only 36 primary and 94 secondary school children could be fully evaluated. A large number of students left the program due to the changes determined by the pandemic situation, which made it impossible for them to participate in all the project activities, because of the lack of internet access or technology. In the primary school sample $(\mathrm{N}=36)$ there were 17 girls and 19 boys with an average age $M=8.7$ ( $S D=1.22$ ). In the secondary school sample $(\mathrm{N}=94)$, there were 44 girls and 50 boys $(39 \%)$ with an average age $\mathrm{M}=13.19(\mathrm{SD}=0.94)$.

\section{Procedure}

After the initial assessment was completed, the students in the target group participated in a series of activities, specific to their age. These group activities took place online and face-to-face, for about eight months. Every week, the project team carried out one hour of remedial education activities on Romanian language and mathematics, one personal development activity, and one school counseling activity. Using stories and games, these last categories of activities were adapted to the child's needs and focused on self-knowledge, socialawareness, emotional development, emotion regulation, social development, communication skills, etc. Depending on the individual needs identified, some 
of the counseling activities were performed individually. At the beginning of the pandemic situation, the activities were performed using WhatsApp video calls (for group and individual activities), and for secondary-school children, later on, in some schools, teachers used Google Classroom. The participants were invited to discuss different topics about who they are, what are their abilities, how they see themselves and what others think of them. Using "Forming, storming, norming, performing" framework (Tuckman, 1965), students have learned to work together, accept and trust each other and so, they became more involved in role play activities and teamwork, they were more willing to express their point of view in debates and art activities. During the intervention, teachers and counselors used therapeutic stories and games, thematic play, expressive writing, drawing, painting etc.

\section{Results}

To assess the effect of the intervention on the competencies proposed for evaluation, we compared the results obtained by the participants in the two moments of the intervention. Because in the case of the BASC questionnaire, the items differ according to age, we have decided to perform a separate analysis of the data. Both in the case of 7-11-year-old students (table 1) and in the case of 11-15-year-olds (table 2), the intervention had the expected effects on several outcomes.

Table 1. The change for the main outcomes in the primary school sample

\begin{tabular}{lccccccc}
\hline \multicolumn{1}{c}{ Outcomes } & \multicolumn{2}{c}{ Pre-intervention } & \multicolumn{2}{c}{ Post-intervention } & & & \\
\hline & $\mathrm{M}$ & $\mathrm{SD}$ & $\mathrm{M}$ & SD & $\mathbf{t}$ & $\mathbf{p}$ & $\mathbf{D}$ \\
\hline Adaptability & 16.69 & 3.29 & 7.94 & 5.54 & -1.43 & 0.161 & 0.48 \\
Social skills & 16.83 & 4.15 & 17.47 & 5.1 & -0.74 & 0.461 & 0.25 \\
Learning skills & 13.47 & 4.87 & 15.22 & 4.82 & -2.14 & 0.039 & 0.72 \\
Affective problems & 4.58 & 3.16 & 3.41 & 2.83 & 2.71 & 0.010 & 0.91 \\
Anxiety problems & 2.77 & 2.02 & 1.11 & 1.08 & 6.45 & 0.001 & 2.18 \\
ADHD problems & 5.33 & 4.05 & 3.25 & 3.04 & 3.96 & 0.001 & 1.33 \\
\hline
\end{tabular}

Note, $\mathrm{N}=36$ 
As can be seen in the table 1, the results confirm statistically significant changes for the majority of the dimensions evaluated, namely: learning skills $(\mathrm{t}=-2.14, \mathrm{p}<0.05)$, affective problems $(\mathrm{t}=2.71, \mathrm{p}=0.010)$, anxiety problems $(t=6.45, p<0.01)$ and specific problems for ADHD $(t=3.96, p<0.01)$. As far as the magnitude of these changes is concerned, the only moderate change $(d=0.72)$ was recorded for learning skills, while for the other 3 outcomes, the magnitude of change was large (varying from $\mathrm{d}=0.91$ for affective problems to 2.18 for anxiety problems).

Table 2. The change for the main outcomes in the secondary school sample

\begin{tabular}{llllllll}
\hline Outcomes & \multicolumn{2}{l}{ Pre-intervention } & \multicolumn{2}{l}{ Post-intervention } \\
\hline & $\mathrm{M}$ & $\mathrm{SD}$ & $\mathrm{M}$ & $\mathrm{SD}$ & $\mathrm{t}$ & $\mathrm{p}$ & $\mathrm{D}$ \\
\hline Learning skills & 12.43 & .84 & 17.22 & 7.48 & -9.18 & 0.001 & 1.90 \\
Adaptability & 15.52 & .57 & 18.29 & 4.42 & -8.32 & 0.001 & 1.72 \\
Social skills & 12.36 & 6.77 & 17.07 & 5.80 & -8.58 & 0.001 & 1.78 \\
Affective problems & 3.84 & 3.49 & 2.18 & 1.99 & 6.63 & 0.001 & 1.37 \\
Anxiety problems & 1.40 & 1.94 & 0.31 & 0.64 & 6.25 & 0.001 & 1.29 \\
ADHD problems & 8.13 & 7.78 & 4.28 & 6.05 & 6.70 & 0.001 & 1.39 \\
\hline
\end{tabular}

Note, $\mathrm{N}=94$

As table 2 shows, there is a significant change for all outcomes: learning skills $(\mathrm{t}=-9.18, \mathrm{p}<0.01)$, adaptability $(\mathrm{t}=-8.32, \mathrm{p}<0.01)$, social skills $(\mathrm{t}=-8.58$, $\mathrm{p}<0.01)$, affective problems $(\mathrm{t}=6.63, \mathrm{p}<0.01)$, anxiety problems $(\mathrm{t}=6.25$, $\mathrm{p}<0.01)$ and ADHD problems ( $\mathrm{t}=6.70, \mathrm{p}<0.01)$. As far as the magnitude of change is concerned, all changes recorded a large magnitude (from $d=1.29$ to $d=1.90$ ).

\section{Correlates of change}

As mentioned above, the aim of our investigation was mainly to measure the effects of the intervention on the emotional and behavioral components of school engagement. Besides the investigation of our hypotheses, we wanted to identify potential correlates of the change in the outcomes, that might become relevant for future similar projects. To quantify the individual change, the 
difference between post and pre-intervention was calculated for each participant involved in both stages of the study. We analyzed as potential correlates of change, variables such as gender, age, ethnicity, parental status, family size (number of children in the family), and attendance in the project activities.

\section{Gender}

The data revealed that for primary school students, there are significant gender differences in the effectiveness of the intervention for social skills, emotional problems, and anxiety problems (table 3), in such a way that the intervention is more effective for girls than for boys. Also, even if for the other outcomes gender differences regarding the mean change were not significant, the tendency of the results is similar, with larger changes for girls.

Table 3. Gender differences in the mean change (post-pre intervention) for both primary and secondary school samples

\begin{tabular}{llllllllllll}
\hline \multicolumn{1}{c}{ Primary school sample (N=36) } & \multicolumn{3}{c}{ Secondary school sample (N=94) } \\
\hline Effectiveness upon & Boys & \multicolumn{3}{c}{ Girls } & \multicolumn{5}{c}{ Boys } & \multicolumn{3}{c}{ Girls } \\
\hline & M & SD & M & SD & t & M & SD & M & SD & t \\
\hline Adaptability & .22 & 5.77 & 2.28 & 4.57 & -1.18 & 2.78 & 3.08 & 2.76 & 3.44 & 0.30 \\
Social skills & -1.28 & 6.30 & 2.56 & 2.64 & $-2.38^{*}$ & 5.05 & 5.56 & 4.28 & 5.04 & 0.69 \\
Learning abilities & .33 & 5.88 & 3.17 & 3.22 & -1.79 & 5.73 & 6.53 & 3.28 & 7.02 & 1.74 \\
Affective problems & -.17 & 2.55 & -2.17 & 2.26 & $2.49^{*}$ & -1.75 & 2.46 & -1.54 & 2.40 & -0.40 \\
Anxiety problems & -1.06 & 1.30 & -2.28 & 1.56 & $2.54^{*}$ & -1.11 & 1.66 & -1.04 & 1.72 & -0.19 \\
ADHD problems & -2.28 & 3.89 & -1.89 & 2.30 & -.36 & -4.67 & 5.88 & -2.83 & 5.03 & -1.60 \\
\hline
\end{tabular}

Note, ${ }^{* *} \mathrm{p}<0.01,{ }^{*} \mathrm{p}<0.05$

As far as the secondary school sample is concerned, also in table 3, we can observe that there are no significant gender differences regarding the 6 outcomes that were analyzed. In other words, for the secondary school sample, the intervention was equally effective for boys and girls. 


\section{Age}

Regarding the age, the results revealed that for secondary school students, age is a significant correlate only for the effectiveness of the intervention on learning skills (table 4), in the sense that the effectiveness of the intervention increases with the age of the students.

Table 4. The correlations between age and the change (post-pre intervention) for both primary and secondary school samples

\begin{tabular}{lcc}
\hline Change in & \multicolumn{2}{c}{ Age } \\
\cline { 2 - 3 } & $\begin{array}{c}\text { Primary school sample } \\
(\mathrm{N}=36)\end{array}$ & $\begin{array}{c}\text { Secondary school sample } \\
(\mathrm{N}=94)\end{array}$ \\
\hline Adaptability & .19 & .16 \\
Social skills & -.10 & .10 \\
Learning abilities & .26 & $.27^{* *}$ \\
Affective problems & .06 & .13 \\
Anxiety problems & -.12 & .07 \\
ADHD problems & -.03 & -.12 \\
\hline
\end{tabular}

Note, ${ }^{* *} \mathrm{p}<0.01,{ }^{*} \mathrm{p}<0.05$

In the case of primary school children, even if age does not correlate significantly with the effectiveness of the intervention, for any of the measured aspects, it can be observed that the magnitude of the correlation with the learning abilities is very similar to the one found for secondary school children. The reason why this value was not significant is the relatively small sample of primary school children, and implicitly the low statistical power.

\section{Ethnicity}

Another potential correlate of change that was investigated was ethnicity. Results are presented in table 5. 
ADRIAN OPRE, RAMONA BUZGAR, SEBASTIAN PINTEA, DANA OPRE, EUGEN SECARĂ

Table 5. Ethnical differences in the effectiveness of the program (ANOVA)

\begin{tabular}{|c|c|c|c|c|c|c|c|c|c|c|c|c|}
\hline \multirow{3}{*}{$\begin{array}{l}\text { Effectiveness } \\
\text { upon }\end{array}$} & \multicolumn{6}{|c|}{ Primary school sample } & \multicolumn{6}{|c|}{ Secondary school sample } \\
\hline & \multicolumn{2}{|c|}{ Romanians } & \multicolumn{2}{|c|}{ Hungarians } & \multicolumn{2}{|c|}{ Rroma } & \multicolumn{2}{|c|}{ Romanians } & \multicolumn{2}{|c|}{ Hungarians } & \multicolumn{2}{|c|}{ Rroma } \\
\hline & M & SD & M & SD & M & SD & M & SD & M & SD & M & SD \\
\hline Adaptability & -1.00 & 5.46 & 1.18 & 4.1 & 3.38 & 5.20 & 2.89 & 3.75 & 2.35 & 2.29 & 2.84 & 2.93 \\
\hline Social skills & -1.83 & 6.21 & 2.18 & 4.69 & 1.62 & 3.78 & 5.29 & 6.20 & 2.59 & 2.15 & 5.03 & 5.00 \\
\hline $\begin{array}{l}\text { Learning } \\
\text { abilities* }\end{array}$ & -1.08 & 5.05 & 5.45 & 3.24 & 1.23 & 4.09 & 4.69 & 7.15 & .76 & 4.68 & 6.63 & 6.62 \\
\hline $\begin{array}{l}\text { Affective } \\
\text { problems }\end{array}$ & -.42 & 2.23 & -2.36 & 2.62 & -.85 & 2.67 & -1.87 & 2.52 & -1.06 & 1.56 & -1.69 & 2.67 \\
\hline $\begin{array}{l}\text { Anxiety } \\
\text { problems* }\end{array}$ & -1.92 & 2.02 & -1.82 & 1.60 & -1.31 & .95 & -1.56 & 1.96 & -.41 & .87 & -.78 & 1.41 \\
\hline $\begin{array}{l}\text { ADHD } \\
\text { problems* }\end{array}$ & -.75 & 2.45 & -2.36 & 1.75 & -3.08 & 4.25 & -3.62 & 5.78 & -1.41 & 1.87 & -5.47 & 6.15 \\
\hline
\end{tabular}

${ }^{* *} \mathrm{p}<0.01,{ }^{*} \mathrm{p}<0.05$

In the case of the primary school sample, significant differences in the effectiveness of the intervention according to ethnicity were recorded only for learning skills $(\mathrm{F}=7.06, \mathrm{p}<0.01)$ in such a way that Hungarian students recorded the larger improvement ( $\mathrm{M}=5.45, \mathrm{SD}=3.24)$.

In the case of the secondary school sample, significant ethnical differences in the effect of the intervention were found for learning abilities $(\mathrm{F}=4.38$, $\mathrm{p}<0.05)$, anxiety problems $(\mathrm{F}=3.86, \mathrm{p}<0.05)$, and ADHD problems $(\mathrm{F}=3.15$, $\mathrm{p}<0.05)$. Thus, at the level of learning abilities, we can see that the biggest improvement occurred for Roma students $(M=6.63, S D=6.62)$, followed by Romanian students ( $M=4.69, S D=7.15)$ and Hungarian students $(M=0.76, S D=4.68)$. Analyzing the anxiety problems, the highest change was registered in Romanian students $(\mathrm{M}=-1.56, \mathrm{SD}=1.96)$ followed by Roma students $(\mathrm{M}=-0.78, \mathrm{SD}=1.41)$ and Hungarian students $(\mathrm{M}=-0.41, \mathrm{SD}=0.87)$. These results could suggest the need for long-term programs addressed to Romanian students, to reduce their anxious moods. These data confirm, moreover, previous results obtained from studies conducted on children in Romania, which suggested that our students 
have high-performance anxiety, and this is an important variable that predicts school dropout. In terms of ADHD problems, the larger change occurred in Roma students ( $\mathrm{M}=-5.47, \mathrm{SD}=6.15)$ followed by Romanian students ( $\mathrm{M}=-3.62$, $\mathrm{SD}=5.78)$ and Hungarian students $(\mathrm{M}=-1.41, \mathrm{SD}=1.87)$. From the teacher's and counselor's reports, role- play activities, playing musical instruments, expressing emotions with musical instruments and movement, the magic circle (safety circle) were the activities in which it was possible to observe the increase of the ability to inhibit the response (impulse), the increase of students' ability to concentrate on the activity etc.

\section{Family context}

Given that the students in the target group come from vulnerable backgrounds, we tried to identify whether the family context in which they spend most of their time can be related to the effect of the intervention (table 6).

Table 6. The family context and effectiveness of the intervention

\begin{tabular}{lc|c|c|c|c|c|c|c|c|c|c|c}
\hline \multicolumn{7}{c|}{ Primary school sample } & \multicolumn{5}{c}{ Secondary school sample } \\
\hline Effectiveness upon & Both parents & \multicolumn{2}{c|}{ Mother } & \multicolumn{2}{c}{ Other } & \multicolumn{2}{c}{ Both parents } & \multicolumn{2}{c}{ Mother } & \multicolumn{2}{c}{ Other } \\
\hline & M & SD & M & SD & M & SD & M & SD & M & SD & M & SD \\
\hline Adaptability** & -4.75 & 4.27 & 2.88 & 3.81 & 3.08 & 4.70 & 2.55 & 3.50 & 3.25 & 2.98 & 1.18 & 3.31 \\
Social skills* & -3.63 & 6.82 & 1.94 & 2.84 & 1.75 & 5.15 & 2.23 & 3.67 & 6.81 & 4.62 & 1.82 & 7.95 \\
Learning abilities & -.88 & 7.72 & 2.88 & 3.32 & 2.00 & 4.02 & 1.61 & 5.89 & 6.54 & 6.24 & 4.18 & 9.15 \\
Affective problems & .13 & 4.05 & -1.19 & 2.07 & -2.00 & 1.71 & -.87 & 1.71 & -2.23 & 2.50 & -1.18 & 3.19 \\
Anxiety problems & -.75 & 2.19 & -1.63 & .96 & -2.33 & 1.50 & -.45 & .85 & -1.37 & 1.72 & -1.55 & 2.70 \\
ADHD problems* & .25 & 3.24 & -2.50 & 3.33 & -3.08 & 2.15 & -2.19 & 2.64 & -5.29 & 5.55 & -1.73 & 9.30 \\
\hline
\end{tabular}

Note, ${ }^{* *} \mathrm{p}<0.01, * \mathrm{p}<0.05$

The results show that in the primary school sample the family context was associated with differences of change for adaptability $(\mathrm{F}=10.39, \mathrm{p}<0.01)$, social skills $(\mathrm{F}=4.18, \mathrm{p}<0.05)$, and ADHD problems $(\mathrm{F}=3.31, \mathrm{p}<0.05)$. For adaptability, the larger improvement was recorded for children interacting mostly with others than their parents $(M=3.08, S D=4.70)$. For social skills, a larger 
improvement was observed for children interacting mostly with their mothers ( $M=1.94, S D=2.84)$. As far as the ADHD problems were concerned, the group with the larger decrease was the group interacting mostly with others than their parents.

In the secondary school sample, the data revealed that the family context was associated with differences of change for social skills $(F=10.97, p<0.01)$, learning abilities ( $\mathrm{F}=5.57, \mathrm{p}<0.01)$, affective problems $(\mathrm{F}=3.46, \mathrm{p}<0.05)$, anxiety problems $(\mathrm{F}=3.51, \mathrm{p}<0.05)$ and ADHD problems $(\mathrm{F}=4.17, \mathrm{p}<0.05)$. In the case of social skills and learning abilities, children who spend most of their time with their mother, recorded the largest improvement $(M=6.81, S D=4.62$ for social skills and $\mathrm{M}=6.54, \mathrm{SD}=6.24$ for learning abilities). Regarding their affective and ADHD problems, also children who spent most of their time with their mothers recorded the largest improvement $(M=-2.23, S D=2.50$ for affective problems and $\mathrm{M}=-5.29, \mathrm{SD}=5.55$ for ADHD problems). As far as the anxiety problems are concerned, children who spent most of their time with others than their parents recorded the largest improvement $(M=-1.55, S D=2.70)$.

\section{Number of children in the family}

Another factor analyzed in relation to the change in the outcomes of the intervention was the number of siblings in each family. Results are presented in table 7.

Table 7. The correlations between the number of children in each family and the change in each outcome of the program

\begin{tabular}{lcc}
\hline Change in & Primary school sample & Secondary school sample \\
\hline Adaptability & .23 & -.04 \\
Social skills & .10 & .17 \\
Learning abilities & .11 & $.24^{*}$ \\
Affective problems & -.01 & -.09 \\
Anxiety problems & .06 & -.07 \\
ADHD problems & -.13 & -.15 \\
\hline
\end{tabular}

Notes, ${ }^{* *} \mathrm{p}<0.01,{ }^{*} \mathrm{p}<0.05$ 
As table 7 shows, in the secondary school sample, the only significant correlate of the change was recorded for the learning abilities $(r=0.24, p<0.05)$. A similar correlation was obtained in the primary school sample, even if not significant (due to the small sample), with the change in adaptability ( $r=0.23)$. In other words, children with more siblings had larger improvements in their learning abilities in the secondary school sample and larger improvements in adaptability in the primary school sample.

The project activities produced a greater leap for these children, as they started the pre-test with low values of learning skills, which means that the specifics of the remedial interventions were well thought out by the project team in relation to their needs. This is extremely informative for educational decision-makers, as it may suggest that the number of siblings may even become a predictor of school dropout (reduced learning skills leading to school failure, a dimension that causes school dropout). The data obtained here can also be used to justify the need for customized interventions for these children from large families, if we want them to have good academic results that ensure their access to high school or even tertiary education.

\section{Marital status of the parents}

Over the years, many researchers found that the structure of the family can play an important role when it comes to school performance, child adjustment to school, or graduating from high school (Sun \& Li, 2008; Manning \& Lamb, 2003). In our study, we also investigated a potential association between family structure (marital status of the parents) and the changes in the outcomes of the intervention program. Results are presented in table 8.

Table 8. The marital status of the parents and intervention effectiveness

\begin{tabular}{|c|c|c|c|c|c|c|c|c|c|c|}
\hline & \multicolumn{5}{|c|}{ Primary school sample } & \multicolumn{5}{|c|}{ Secondary school sample } \\
\hline \multirow{2}{*}{$\begin{array}{l}\text { Effective- } \\
\text { ness upon }\end{array}$} & \multicolumn{2}{|c|}{ Married } & \multicolumn{2}{|c|}{ Other } & & \multicolumn{2}{|c|}{ Married } & \multicolumn{2}{|c|}{ Other } & \\
\hline & $\mathrm{M}$ & SD & $\mathrm{M}$ & SD & $\mathrm{t}$ & $M$ & SD & $\mathrm{M}$ & SD & $\mathrm{t}$ \\
\hline Adaptability & .50 & 5.45 & .92 & 4.68 & -.22 & 2.88 & 3.20 & 2.61 & 3.33 & 0.69 \\
\hline Social skills & 1.71 & 5.58 & 1.83 & 3.30 & -.07 & 4.47 & 4.75 & 5.11 & 6.18 & 0.57 \\
\hline
\end{tabular}


ADRIAN OPRE, RAMONA BUZGAR, SEBASTIAN PINTEA, DANA OPRE, EUGEN SECARĂ

\begin{tabular}{|l|c|c|c|c|c|c|c|c|c|c|}
\hline & \multicolumn{5}{|c|}{ Primary school sample } & \multicolumn{5}{|c|}{ Secondary school sample } \\
\hline $\begin{array}{l}\text { Learning } \\
\text { abilities }\end{array}$ & .29 & 5.24 & 3.17 & 4.88 & -1.58 & 4.03 & 6.64 & 5.61 & 7.12 & 0.27 \\
\hline $\begin{array}{l}\text { Affective } \\
\text { problems }\end{array}$ & -.79 & 2.81 & -1.92 & 1.93 & 1.24 & -1.31 & 2.07 & -2.22 & 2.85 & 0.10 \\
\hline $\begin{array}{l}\text { Anxiety } \\
\text { problems }\end{array}$ & -1.79 & 1.82 & -1.42 & .79 & -.86 & -.83 & 1.23 & -1.50 & 2.18 & 0.09 \\
\hline $\begin{array}{l}\text { ADHD prob- } \\
\text { lems }\end{array}$ & -1.33 & 3.07 & -3.58 & 2.87 & $2.11^{*}$ & -4.10 & 5.35 & -3.44 & 5.96 & 0.58 \\
\hline
\end{tabular}

Note, ${ }^{* *} \mathrm{p}<0.01,{ }^{*} \mathrm{p}<0.05$

In our study, the only difference in the effectiveness of the intervention depending on the status of the parents is manifested for ADHD problems in the case of primary school children.

Thus, students who have divorced parents, separated or live with one parent, have larger improvements in their ADHD problems following the intervention.

\section{Attendance in the program}

The last factor analyzed here is the attendance in the program. Results are presented in table 9.

Table 9. The correlations between the attendance of the program and the effectiveness of the program

\begin{tabular}{lcc}
\hline Effectiveness upon & Primary school sample & Secondary school sample \\
\hline Adaptability & .32 & .14 \\
Social skills & .15 & $.32^{* *}$ \\
Learning abilities & .01 & .04 \\
Affective problems & .17 & -.04 \\
Anxiety problems & .16 & -.09 \\
ADHD problems & -.22 & -.05 \\
\hline
\end{tabular}

Notes, ${ }^{* *} \mathrm{p}<0.01,{ }^{*} \mathrm{p}<0.05$ 
As table 9 shows, in the secondary school sample, the only significant correlate of the change was recorded for the social skills $(r=0.32, p<0.01)$. An identical correlation was obtained in the primary school sample, even if not significant (due to the small sample), with the change in adaptability ( $r=0.32$ ). In other words, children with a higher level of attendance had larger improvements in their social skills in the secondary school sample and larger improvements in adaptability in the primary school sample. Also notable, even if not significant, is the correlation between attendance and the change in ADHD problems in the primary school sample. That is, children with higher levels of attendance had larger decreases in their ADHD problems.

\section{Conclusions and implications}

In the effort to reduce school drop-out and keep children in school for as much as it is possible, the most effective strategies involve preventive and corrective interventions for children at risk of dropping out of school before entering high school. These interventions require additional support (e.g. guidance, counseling), as well as actions to monitor risk factors, which allow for the correct guidance of interventions. There are aspects that the decision-makers and the people directly involved in the implementation, within this project, have capitalized on. Moreover, the intervention itself also has to aim at carrying out activities that can lead to increased school performance, involvement in school activities, and thus to the extension of the schooling period by (a) providing direct, individualized guidance and support for the fulfillment of homework, participating in-class activities; (b) participation of the student in counseling and career guidance classes which may sustain a positive attitude toward education. Therefore, we can unequivocally state that the results obtained within the project, come to confirm and complete the data seen in other similar studies found in the international and national literature. We summarize some of the most relevant: 1. gender, ethnicity, family environment are vulnerabilities that over time can lead to the phenomenon of school dropout. 2. for school students, socio-emotional and cognitive competencies develop asynchronously and 
therefore an inappropriate development of them can facilitate school dropout or class repetition. 3. children with normally developed socio-emotional competencies and a high degree of adaptability are more likely to constantly participate in remedial activities. 4. the presence of parents and especially mothers in children's lives can ensure the emotional stability of children and adolescents. 5. adolescents deprived of parental involvement may develop more serious emotional and behavioral problems and are therefore vulnerable to the temptation to leave school 6. there are gender and age differences in the development of certain specific skills 7. personal and academic development activities reduce the level of anxiety experienced by school students 8 . overall, the intervention implemented in the project has significant effects both in terms of socio-emotional development, but also in terms of adaptability and learning skills of children in the target group.

Obviously, in the context of any study, there are some limitations. We draw attention to the fact that not all dimensions have changed. This may be due to several factors: the small number of children left in the project and implicitly the low statistical power for some analyses, especially at the primary level (pre-test vs. post-test), changes due to the natural maturation of children and adolescents, the pandemic generated by the new coronavirus, the lack of a true control group (which was excluded for both ethical and practical reasons). However, analyzing the data objectively, there are sufficient arguments to support the existence of changes in the developmental profile of students and we are talking here about the size of the effect recorded and explained for each dimension assessed. In conclusion, the results of this study confirmed that the multidimensional intervention carried out within the project, generally led to changes according to expectations. The intervention included both remedial activities (to increase school performance) and social and emotional development activities. Initial data revealed that at the time of the first evaluation, social skills were not sufficiently developed for about half of the students. In addition, more than a third of them had serious emotional problems and noticeable skills gaps that impair the autonomous learning process. The need for interventions on these specific dimensions is sustained by the fact that socio-emotional competencies are critical for academic success, but also for professional/ personal 
success. This also applies to children and adolescents who are at increased risk of dropping out of school due to disadvantaged socio-economic status, ethnic minority status, or early emotional and/or behavioral problems (Domitrovich, Durlak, Staley \& Weissberg, 2017). The well-known process by which these skills are acquired is that of socio-emotional learning (SEL- social and emotional learning) (Weissberg, Durlak, Domitrovich \& Gullota, 2015; Benga et al., 2018; Buzgar, Dumulescu \& Opre, 2013).). As such, as we have done in this case, for similar situations we consider that it is necessary to plan and implement some effective, multilevel interventions focused on cognitive, emotional, and behavioral engagement in school activities. In conclusion, we can say that the intervention has statistically significant effects that are in line with the general purpose of the project, namely to reduce school dropout, to support the education of future generations, and to take into account especially vulnerable groups.

\section{Acknowledgement}

This research was supported by Human Capital Operational Program, project POCU/ 74/6/18/104571 "School for all - access to quality education for preschoolers, schoolchildren and teachers from the Nord-West Region".

\section{REFERENCES}

Archambault, I., Janosz, M., Fallu, J. S., \& Pagani, L. S. (2009). Student engagement and its relationship with early high school dropout. Journal of Adolescence, 32, 651670. https://doi.org/10.1016/j.adolescence.2008.06.007

Benga, O., Buzgar., R, Dumulescu, D., Opre, A., Pintea, S., (2018), Analiza practicilor psiho-educationale privind dezvoltarea abilitatilor non-cognitive la copii si adolescenti, Bucuresti, Ed. Alpha MDN, ISBN 978-973-139-393-3 
ADRIAN OPRE, RAMONA BUZGAR, SEBASTIAN PINTEA, DANA OPRE, EUGEN SECARĂ

Brown, B. B. (2004). Adolescents' relationships with peers. In R. M. Lerner, \& L. Steinberg (Eds.), Handbook of adolescent psychology (pp. 363394). New York: Wiley. Available from https://doi.org/10.1002/9780471726746.ch12

Buzgar, R., Dumulescu, D., Opre, A., (2013). Emotional and Social Problems in Primary School Children: a National Screening Program, PSIWORLD 2012, Procedia - Social and Behavioral Sciences, 78, 250-254

DiPerna, J. C., Volpe, R. J., \& Elliott, S. N. (2002). A model of academic enablers and elementary reading/language arts achievement. School Psychology Review, 31(3), 298-312.

Domitrovich C.E, Durlak J.A, Staley K.C, Weissberg R.P. (2017). Social-Emotional Competence: An Essential Factor for Promoting Positive Adjustment and Reducing Risk in School Children. Child Development, 88(2):408-416. doi: 10.1111/cdev.12739.

Fredricks, J. A., Blumenfeld, P. C., \& Paris, A. H. (2004). School engagement: Potential of the concept, state of the evidence. Review of Educational Research, 74(1), 59109. Available from https://doi.org/10.3102/00346543074001059.

Furrer, C., \& Skinner, E. (2003). Sense of relatedness as a factor in children's academic engagement and performance. Journal of Educational Psychology, 95(1), 148162. https://doi.org/10.1037/0022-0663.95.1.148

Green, J., Liem, G. A. D., Martin, A. J., Colmar, S., Marsh, H. W., \&McInerney, D. (2012). Academic motivation, self-concept, engagement, and performance in high school: Key processes from a longitudinal perspective. Journal of Adolescence, 35, 11111122. https:// doi.org/10.1016/j.adolescence.2012.02.016.

Lam, S. F., Jimerson, S., Shin, H., Cefai, C., Veiga, F. H., Hatzichristou, C., ... Zollneritsch, J. (2015). Cultural universality and specificity of student engagement in school: The results of an international study from 12 countries. The British Journal of Educational Psychology, 86(1), 137- 153. https://doi.org/10.1111/bjep.12079.

Manning, W. M. \& Lamb, K., (2003). "Adolescent Well-Being in Cohabitating, Married, and Single-Parent Families," Journal of Marriage and Family 65, 876-893.

Martin, A., Way, J., Bobis, J., \& Anderson, J. (2014). Exploring the ups and downs of mathematics engagement in the middle years of school. The Journal of Early Adolescence, 35(2), 199-244. https://doi.org/10.1177/0272431614529365.

Organization for Economic Cooperation and Development (OECD). (2016). PISA 2015 Results (Volume II): Policies and Practices for Successful Schools, PISA, OECD Publishing, Paris, https://doi.org/10.1787/9789264267510-en. 
FOSTERING SCHOOL ENGAGEMENT IN CHILDREN FROM DISADVANTAGED COMMUNITIES

Organization for Economic Cooperation and Development (OECD). (2017). PISA 2015 Results (Volume III): Students' Well-Being, PISA, OECD Publishing, Paris, https://doi.org/10.1787/9789264273856-en.

Patall, E. A., Steingut, R. R., Vasquez, A. C., Trimble, S. S., Pituch, K. A., \& Freeman, J. L. (2017). Daily autonomy supporting or thwarting and students' motivation and engagement in the high school science classroom. Journal of Educational Psychology. Available from https://doi. org/10.1037/edu0000214

Pino-James,N., Shernoff, D.J., Bressler,D.M., Larson, S.C. Sinha,S., (2019).Chapter 8 - Instructional Interventions That Support Student Engagement: An International Perspective, in Jennifer A. Fredricks, Amy L. Reschly, Sandra L. Christenson,(Eds). Handbook of Student Engagement Interventions, Elsevier Academic Press, Pages 103-119, ISBN 9780128134139, https://doi.org/10.1016/B978-0-12-8134139.00008-5.

Rumberger, R. (2011). Dropping Out: Why Students Drop Out of High School and What Can Be Done About It. Cambridge, MA and London, England: Harvard University Press. https://doi.org/10.4159/harvard.9780674063167

Shernoff, D. J., Ruzek, E., \& Sinha, S. (2016). The influence of the high school classroom environment on learning as mediated by student engagement. School Psychology International, 38(2), 201-218. https://doi.org/10.1177/0143034316666413

Skinner, E. A., \& Pitzer, J. R. (2012). Developmental dynamics of student engagement, coping, and everyday resilience. In S. L. Christenson, A. L. Reschly, \& C. Wylie (Eds.), Handbook of research on student engagement (pp. 2144). New York: Springer. Available from https://doi. org/10.1007/978-1-4614-2018-7_2.

Sun, Y. \& Li, Y. (2008). Parents' marital disruption and its uneven effect on children's academic performance - A simulation model. Social science research. 37. 449-60. Doi:10.1016/j.ssresearch.2007.03.005.

Weissberg, R. P., Durlak, J. A., Domitrovich, C. E., \&Gullotta, T. P. (Eds.). (2015). Social and emotional learning: Past, present, and future. In J. A. Durlak, C. E. Domitrovich, R. P. Weissberg, \& T. P. Gullotta (Eds.), Handbook of social and emotional learning: Research and practice (pp. 3-19). The Guilford Press. 